TP Periodica Polytechnica Electrical Engineering and Computer Science

61(3), pp. 253-263, 2017

https://doi.org/10.3311/PPee.10428

Creative Commons Attribution (i)

RESEARCH ARTICLE

\section{A Novel Modified DTC-SVM Method with Better Overload-capability for Permanent Magnet Synchronous Motor Servo Drives}

\author{
Tibor Vajsz ${ }^{1 *}$, László Számel ${ }^{1}$, György Rácz ${ }^{2}$
}

Received 21 December 2016; accepted after revision 21 February 2017

\begin{abstract}
Direct torque control with space vector modulation (DTCSVM) is one of the most promising alternatives of field-oriented control in the case of permanent magnet synchronous motor drives. This method controls the electromagnetic torque of the motor with excellent dynamics which makes it an attractive choice in the case of servo drives. In this article DTC-SVM is investigated with Matlab-Simulink simulation and it is proven that DTC-SVM has severe instability-issues during overloading and its overload-capabilities are heavily dependent on the speed. Therefore, a novel modified DTC-SVM method is proposed which is stable during overloading and its overload-capabilities are practically independent of the speed. Also, the overload-capability of the new method is superior to that of classical DTC-SVM, while the two methods are practically identical from the point of view of the torque-control dynamics and the torque-ripple generated.
\end{abstract}

\section{Keywords}

permanent magnet synchronous motor, direct torque control, space vector modulation, servo drive, frequency converter, electric drive

\footnotetext{
${ }^{1}$ Department of Electric Power Engineering, Faculty of Electrical Engineering and Informatics, Budapest University of Technology and Economics, H-1521 Budapest, P.O.B. 91, Hungary

${ }^{2}$ Department of Control Engineering and Information Technology, Faculty of Electrical Engineering and Informatics, Budapest University of Technology and Economics, H-1117 Budapest, P.O.B. 91, Hungary

*Corresponding author, e-mail: vajsz.tibor@vet.bme.hu
}

\section{Introduction}

Direct torque control with space vector modulation is a modification of the original direct torque control (DTC) method [1-3]. The excellent dynamic torque-control capabilities of traditional DTC are well known in the literature for permanent magnet synchronous motors and for other motor types as well [4-9]. However, there are serious disadvantages and among them the most important are: varying switching frequency and the excessive amount of torque-ripple generated [10-12]. DTC-SVM solves these problems, as it uses fixed switching frequency and the torque-ripple is significantly reduced compared to DTC, while the dynamics of the torque-control is essentially identical to that of traditional DTC [13-15]. Therefore, DTC-SVM is currently considered as one of the most promising alternatives of the nowadays widely used field-oriented control $[16,17]$.

DTC-SVM was introduced in [1-3]. These publications highlighted the main advantages of DTC-SVM. Since then many investigations have been carried out for this method. Special applications requiring high dynamic performance, excellent efficiency and high precision have been examined such as artillery speed servo systems [18], electric vehicles [19], electric pitch servo systems for wind generators [20]. Also, asymmetric permanent magnet synchronous machines have been investigated and special solutions have been invented for these machines [21]. In order to improve the performance of DTC-SVM several modifications have been developed. Most of the modifications aim at reducing the torque-ripple, increasing the dynamic performance and the efficiency of the method [22-28]. Sensorless methods using extended Kalman-filter have also been invented [29].

However, the overload-capabilities of DTC-SVM and its stability during overloading have not been investigated yet. This article deals with these issues and suggests a modified DTCSVM (MDTC-SVM) method which has significantly improved overload-capabilities and it is stable during overloading. 
2 Vector-control of permanent magnet synchronous motor drives

The basic equations of permanent magnet synchronous motors (PMSM) can be derived from (1) and (2). Equation (1) is called the stator voltage space vector equation and it is as follows $[4,5]$ :

$$
\bar{v}=R \bar{i}+\frac{d \bar{\psi}}{d t}+j \omega_{c} \bar{\psi}
$$

Where:

$\bar{v}:$ the stator voltage space vector (shortly: vector)

$R$ : the stator resistance

$\bar{i}$ : the stator current vector

$\bar{\psi}:$ the stator flux vector

$\omega_{c}$ : the electrical angular velocity of the common coordinate system

Equation (2) defines the electromagnetic torque of the motor [30, 31]:

$$
\bar{m}=\frac{3}{2} p \bar{\psi} \times \bar{i}
$$

where $p$ is the number of pole-pairs.

It is reasonable to choose a common coordinate system where the real axis is fixed to the poleflux-vector (Fig. 1). This coordinate system is called the " $\mathrm{d}$-q" coordinate system [32], where the real axis is called the "direct-axis" (shortly: "d-axis") and the imaginary axis is called the "quadrature-axis" (shortly: "q-axis"). The direct- and the quadrature-axis components of the stator flux vector are as follows [33]:

$$
\begin{gathered}
\psi_{d}=\psi_{p}+L_{d} i_{d} \\
\psi_{q}=L_{q} i_{q}
\end{gathered}
$$

Where:

$\psi_{p}$ : the amplitude of the poleflux-vector

$L_{d}, L_{q}:$ the direct- and the quadrature-axis synchronous inductances

$i_{d}, i_{q}$ : the direct- and the quadrature-axis components of the stator current vector

Substituting (3) and (4) into (1) the relationships between the direct- and the quadrature-axis components of the stator voltage- and current vectors are the following $[4,5]$ :

$$
\begin{gathered}
\frac{v_{d}}{R}+\omega T_{q} i_{q}=i_{d}+T_{d} \frac{d i_{d}}{d t} \\
\frac{v_{q}}{R}-\omega T_{d} i_{d}-\frac{\omega \psi_{p}}{R}=i_{q}+T_{q} \frac{d i_{q}}{d t}
\end{gathered}
$$

Where:

$v_{d}, v_{q}$ : the direct-and the quadrature-axis components of the stator voltage vector $\omega$ : the electrical angular velocity of the poleflux-vector $T_{d}, T_{q}:$ the direct- and the quadrature-axis electrical time constants

$T_{d}$ and $T_{q}$ electrical time constants are defined as follows:

$$
\begin{gathered}
T_{d}=\frac{L_{d}}{R} \\
T_{q}=\frac{L_{q}}{R}
\end{gathered}
$$

Substituting (3) and (4) into (2) the following equation can be derived for the absolute value of the electromagnetic torque:

$$
m=\frac{3}{2} p\left(\psi_{p} i \sin \left(\vartheta_{p}\right)+\frac{L_{d}-L_{q}}{2} i^{2} \sin \left(2 \vartheta_{p}\right)\right)
$$

where $i$ is the amplitude of the stator current vector and $\vartheta_{p}$ is the torque-angle (see Fig. 2).

The electromagnetic torque consists of two components: the excitation torque and the reluctance torque. In the case of most permanent magnet synchronous servo motors the direct- and the quadrature-axis synchronous inductances are nearly identical, thus the reluctance torque is negligible [5]. Therefore this article assumes that $L_{d}=L_{q}$. In this case (9) can be rewritten as:

$$
m=\frac{3}{2} p \psi_{p} i \sin \left(\vartheta_{p}\right)=\frac{3}{2} p \psi_{p} i_{q}
$$

Newton's second law of motion for rotating electrical machines is the following:

$$
\omega_{r}=\frac{1}{J} \int_{0}^{\tau}\left(m_{e}(t)-m_{l}(t)\right) d t+\omega_{r 0}
$$

Where:

$\omega_{r}$ : the mechanical angular velocity of the rotor

$J$ : the moment of inertia for the total system reduced to the shaft of the motor

$m_{e}(t)$ : the electromagnetic torque of the motor

$m_{l}(t)$ : the load torque (reduced to the shaft of the motor)

$\omega_{r 0}:$ the initial mechanical angular velocity of the rotor

In this model the friction-torque is taken into account as a component of the load-torque, therefore the motor-torque equals to the electromagnetic torque. Also, iron-losses of the stator are neglected. Equations (5), (6), (10), (11) together form the differential-equation system of the complete drive system.

\subsection{Coordinate-transformations}

Most vector-control methods require coordinate-transformations during the implementation. In this section only the most common coordinate-transformations will be summarized shortly. Fig. 1 shows the most commonly used coordinate-systems: the "abc" coordinate-system, the " $\mathrm{x}-\mathrm{y}$ " coordinate-system 
and the d-q coordinate-system. The former two coordinate-systems are stationary coordinate-systems, while the d-q coordinate-system is rotating with the poleflux-vector. Both the xy- and the dq coordinate-systems use Cartesian-coordinates, while the abc coordinate-system uses phase quantities.

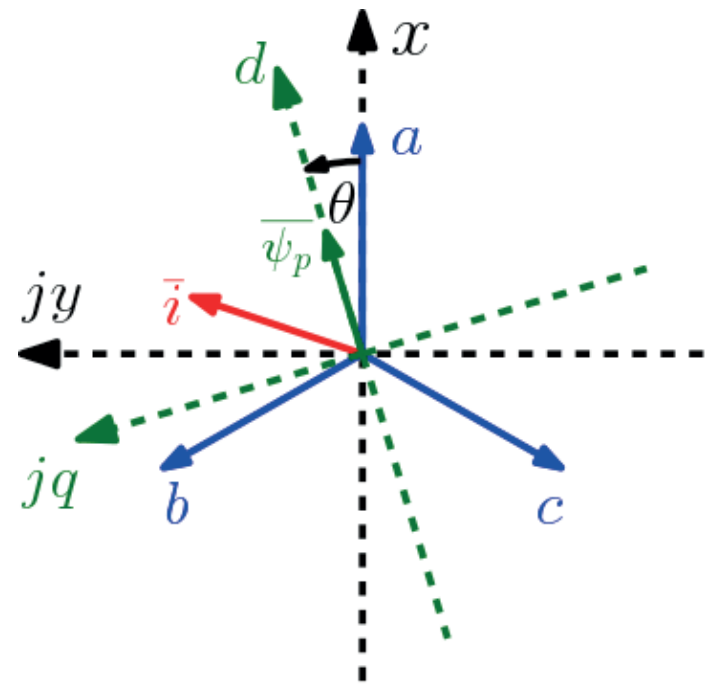

Fig. 1 Coordinate-systems [34]

The "abc-to-xy" transformation performs the transformation of the phase quantities into the $\mathrm{x}-\mathrm{y}$ coordinate-system. For stator currents this can be expressed as:

$$
\begin{gathered}
i_{x}=i_{a} \\
i_{y}=\left(i_{a}+2 i_{b}\right) / \sqrt{3}
\end{gathered}
$$

The "xy-to-dq" transformation performs the transformation from the $\mathrm{x}-\mathrm{y}$ coordinate-system to the $\mathrm{d}-\mathrm{q}$ coordinate-system. For the stator current vector this can be expressed as:

$$
\begin{aligned}
& i_{d}=i_{x} \cos \theta+i_{y} \sin \theta \\
& i_{q}=-i_{x} \sin \theta+i_{y} \cos \theta
\end{aligned}
$$

where $\theta$ is the rotor-angle in electrical degrees. Similarly, the "dq-to-xy" transformation for the stator current vector is:

$$
\begin{aligned}
& i_{x}=i_{d} \cos \theta-i_{q} \sin \theta \\
& i_{y}=i_{d} \sin \theta+i_{q} \cos \theta
\end{aligned}
$$

And the "xy-to-abc" transformation is:

$$
\begin{gathered}
i_{a}=i_{x} \\
i_{b}=\left(-i_{x}+\sqrt{3} i_{y}\right) / 2 \\
i_{c}=\left(-i_{x}-\sqrt{3} i_{y}\right) / 2
\end{gathered}
$$

\subsection{Direct torque control with space vector modulation}

For surface-mounted permanent magnet synchronous motors (2) can be further expressed as:

$$
\begin{aligned}
\bar{m} & =\frac{3}{2} p \bar{\psi} \times \bar{i}=\frac{3}{2} p\left(\overline{\psi_{p}}+L_{d} \bar{i}\right) \times \bar{i}=\frac{3}{2} p \overline{\psi_{p}} \times \bar{i} \\
& =\frac{3}{2} p \overline{\psi_{p}} \times \frac{\bar{\psi}-\overline{\psi_{p}}}{L_{d}}=\frac{3}{2} p \frac{\overline{\psi_{p}} \times \bar{\psi}}{L_{d}}
\end{aligned}
$$

Thus, the absolute value of the electromagnetic torque:

$$
m=\frac{3}{2} p \frac{\psi_{p} \psi \sin \delta}{L_{d}}
$$

where $\psi$ is the amplitude of the stator flux vector and $\delta$ is the load-angle (the angle between the stator flux vector and the poleflux-vector, see Fig. 2).

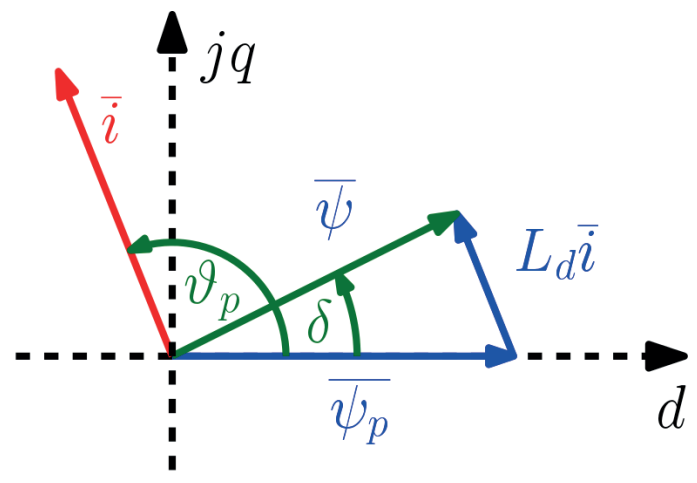

Fig. 2 Vector and angle definitions [35, 36]

According to (22) the electromagnetic torque can be regulated by controlling the amplitude of the stator flux vector and the load-angle. This is the basic principle of direct torque control with space vector modulation (DTC-SVM). Fig. 3 shows the block diagram of the complete control system [1-3].

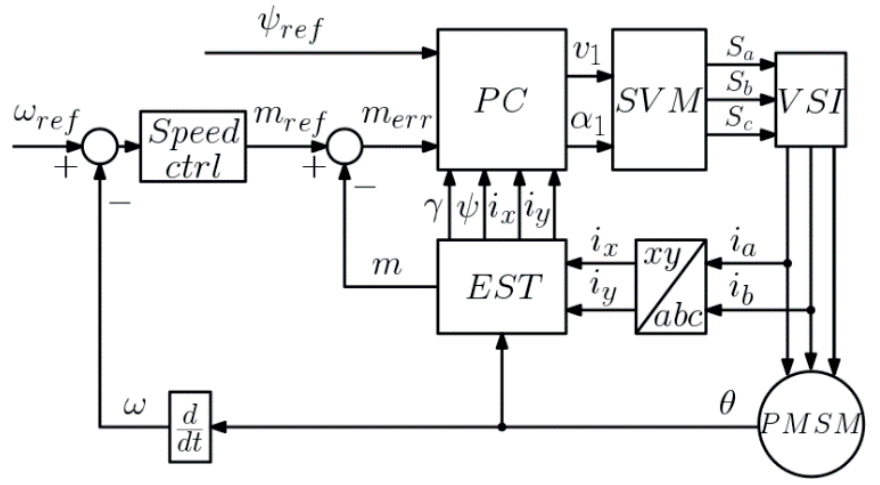

Fig. 3 DTC-SVM $[2,3]$

According to Fig. 3, the stator flux amplitude reference signal $\left(\psi_{\text {ref }}\right)$ and the torque-error signal $\left(m_{e r r}\right)$ are fed to a predictive controller $(P C)$, which produces the voltage reference 
signal $\left(v_{1}\right.$ and $\left.\alpha_{1}\right)$ that is fed to the space vector modulator $(S V M)$. The stator flux vector and the electromagnetic torque are estimated by an estimator (EST) which uses the stator current vector (expressed in the $\mathrm{x}-\mathrm{y}$ coordinate-system) and the rotor angle (in electrical degrees) as input parameters. Fig. 4 shows the block-diagram of the predictive controller.

The predictive controller uses a $\delta$-controller - which is in default a PI-controller - that forms the $\delta$-increment signal $(\Delta \delta)$ based on the torque-error signal. The $\delta$-increment signal is added to the actual angle of the stator flux vector $(\gamma)$ in order to form the stator flux angle reference signal $\left(\gamma_{\text {ref }}\right)$.

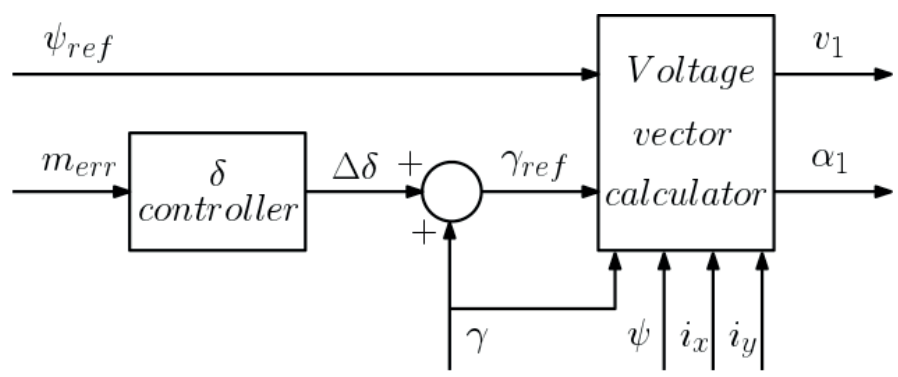

Fig. 4 Predictive controller [2]

The voltage vector calculator block produces the stator voltage vector reference based on the stator flux vector reference, using the following equations:

$$
\begin{gathered}
v_{x, r e f}=\frac{\psi_{r e f} \cos (\gamma+\Delta \delta)-\psi \cos \gamma}{T_{s}}+R i_{x} \\
v_{y, r e f}=\frac{\psi_{r e f} \sin (\gamma+\Delta \delta)-\psi \sin \gamma}{T_{s}}+R i_{y} \\
v_{1}=\sqrt{v_{x, r e f}^{2}+v_{y, r e f}^{2}} \\
\alpha_{1}=\operatorname{atan} \frac{v_{y, r e f}}{v_{x, r e f}}
\end{gathered}
$$

where $T_{s}$ is the controller sample time. Lastly, Fig. 5 shows the block-diagram of the estimator.

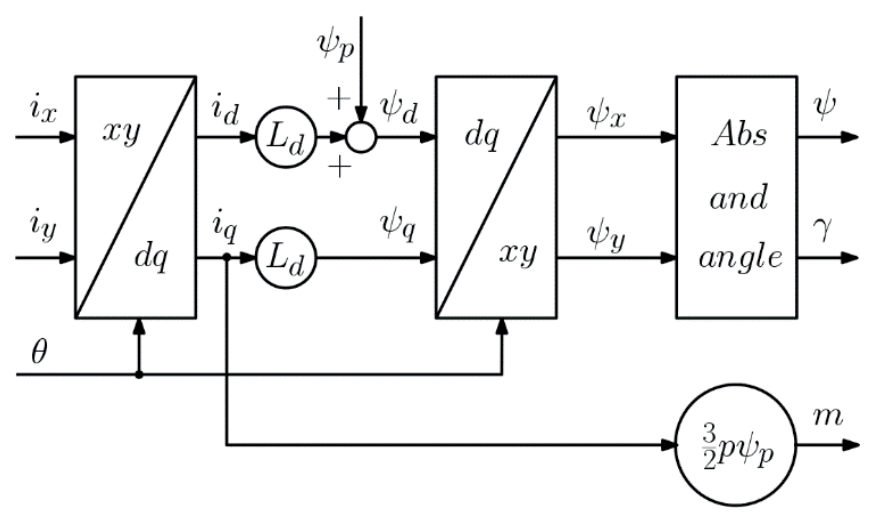

Fig. 5 Estimator [3]
The amplitude and the angle of the stator flux vector can be calculated as follows:

$$
\begin{gathered}
\psi=\sqrt{\psi_{x}^{2}+\psi_{y}^{2}} \\
\gamma=\operatorname{atan} \frac{\psi_{y}}{\psi_{x}}
\end{gathered}
$$

The estimator uses (10) for calculating the electromagnetic torque.

\subsection{Space vector modulation}

In this article a two-level voltage-source inverter (VSI) is assumed as power electronics topology. Fig. 6 shows the voltage vectors belonging to the switching states of the inverter (shortly: inverter-vectors).

Because each of the three legs of the inverter can have two states, there are $2^{3}=8$ switching vectors that can be utilized for the synthesis of the reference stator voltage vector: six active vectors $(\bar{v}(1), \ldots, \bar{v}(6))$ and two zero vectors $(\bar{v}(7)$ and $\bar{v}(8)$, marked as $\bar{v}(0)$ on Fig. 6 for better visibility).

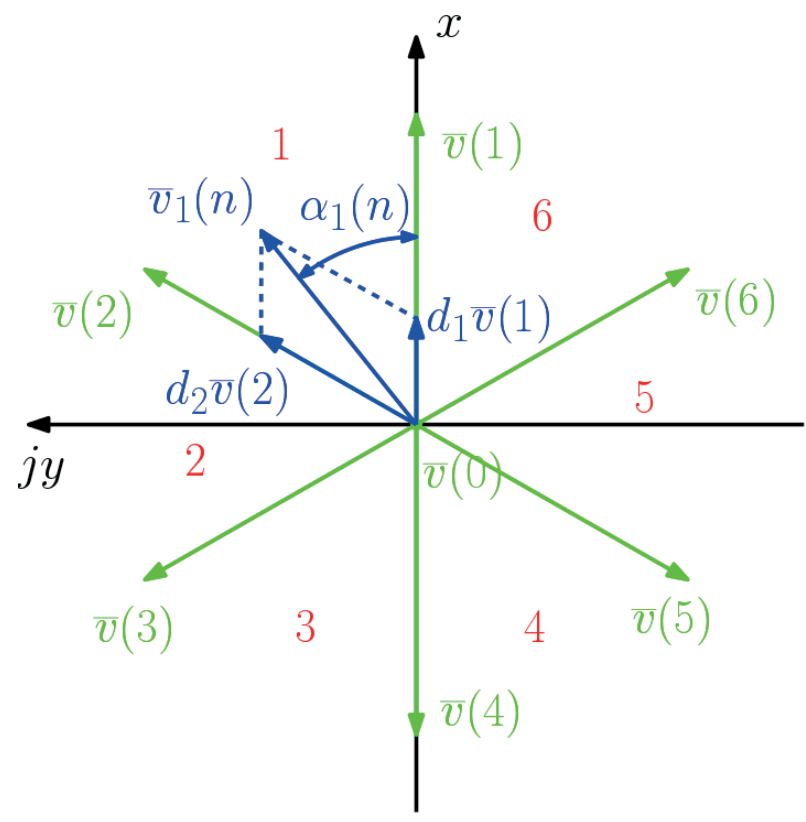

Fig. 6 Space vector modulation $[4,5]$

The active voltage vectors are:

$$
\bar{v}(k)=\frac{2}{3} v_{d c} e^{j(k-1) 60^{\circ}}
$$

where $k=1,2,3 \ldots, 6$ and $v_{d c}$ is the DC-bus voltage $[37,38]$. In each PWM-period the reference voltage vector $\left(\bar{v}_{1}(n)\right.$ on Fig. 6$)$ is synthesised as the linear combination of the neighbouring vectors of the current sector (the sector numbers are marked with red on Fig. 6). The two zero vectors are neighbouring vectors to all of the six sectors (the one should be chosen that leads to the minimal number of switching per PWM-periods). For example, 
if the reference voltage vector is located in the first sector (like on Fig. 6) vectors $\bar{v}(1), \bar{v}(2)$ and $\bar{v}(0)$ can be used for the synthesis of the reference voltage vector. The required duty cycles of the inverter-vectors are the following:

$$
\begin{gathered}
d_{1}=\frac{\sqrt{3} v_{1}(n)}{v_{d c}} \sin \left(60^{\circ}-\alpha_{1}(n)\right) \\
d_{2}=\frac{\sqrt{3} v_{1}(n)}{v_{d c}} \sin \alpha_{1}(n) \\
d_{0}=1-d_{1}-d_{2}
\end{gathered}
$$

Where:

$d_{1}, d_{2}, d_{3}$ : the required duty cycles of the $\bar{v}(1), \bar{v}(2)$ and the $\bar{v}(0)$ inverter-vectors, respectively

$v_{1}(n)$ : the amplitude of the reference stator voltage vector in the $\mathrm{n}^{\text {th }}$ sampling period

$\alpha_{1}(n)$ : the angle of the reference stator voltage vector (in the xy coordinate system) in the $\mathrm{n}^{\text {th }}$ sampling period

\subsection{Simulation results for DTC-SVM}

Simulation was carried out for a synchronous servo motor in Matlab-Simulink environment, using the parameters in Table 1. Investigations are carried out for the normal operation region only.

Table 1 Simulation parameters

\begin{tabular}{ll}
\hline Motor nominal speed & $3000 \mathrm{rpm}$ \\
\hline Motor number of pole-pairs & 3 \\
\hline Motor nominal torque & $1.3 \mathrm{Nm}$ \\
\hline Motor nominal current & $1.4 \mathrm{~A}_{\mathrm{RMS}}$ \\
\hline$R$ & $9.9 \Omega$ \\
\hline$L_{d}$ & $18.6 \mathrm{mH}$ \\
\hline$\psi_{p}$ & $0.1481 \mathrm{~Wb}$ \\
\hline DC-bus voltage & $530 \mathrm{~V}$ \\
\hline Moment of inertia of the whole system, & $2.36 \mathrm{kgcm}{ }^{2}$ \\
reduced to the shaft of the motor & $10 \mathrm{kHz}$ \\
\hline PWM-frequency & $100 \mu \mathrm{s}$ \\
\hline Torque-control loop sampling time & $200 \mu \mathrm{s}$ \\
\hline Speed-control loop sampling time & $1 \mu \mathrm{s}$ \\
\hline Simulation sample time &
\end{tabular}

The simulation uses the optimized switching strategy for space vector modulation detailed in [4, 5]. Current-limitation was also implemented during the investigations, which switches the zero vector on the motor if an overcurrent condition occurs. The stator flux amplitude reference signal was set to its nominal value.

The simulated process is the following. There is a speed-reference step at $0 \mathrm{~ms}$ and after that load-torque steps at $100 \mathrm{~ms}$,
$200 \mathrm{~ms}$ and at $300 \mathrm{~ms}$, respectively (see Fig. 7). Investigations are carried out for torque-ripple and for various speed-references: $0 \mathrm{rpm}, 1000 \mathrm{rpm}, 2000 \mathrm{rpm}$ and $3000 \mathrm{rpm}$. The loadtorque is always the same: $0 \mathrm{Nm}$ between $0 \mathrm{~ms}$ and $100 \mathrm{~ms}$, $2 \mathrm{Nm}$ (154\% of the nominal torque) between $100 \mathrm{~ms}$ and 200 $\mathrm{ms}, 1 \mathrm{Nm}$ (77\% of the nominal torque) between $200 \mathrm{~ms}$ and $300 \mathrm{~ms}$ and $0.5 \mathrm{Nm}$ (38\% of the nominal torque) between $300 \mathrm{~ms}$ and $400 \mathrm{~ms}$. Fig. 7 shows the complete process for a $3000 \mathrm{rpm}$ speed-reference. Table 2 shows the results for the RMS of the torque-ripple, which is shown in percentage of the mean-torque.

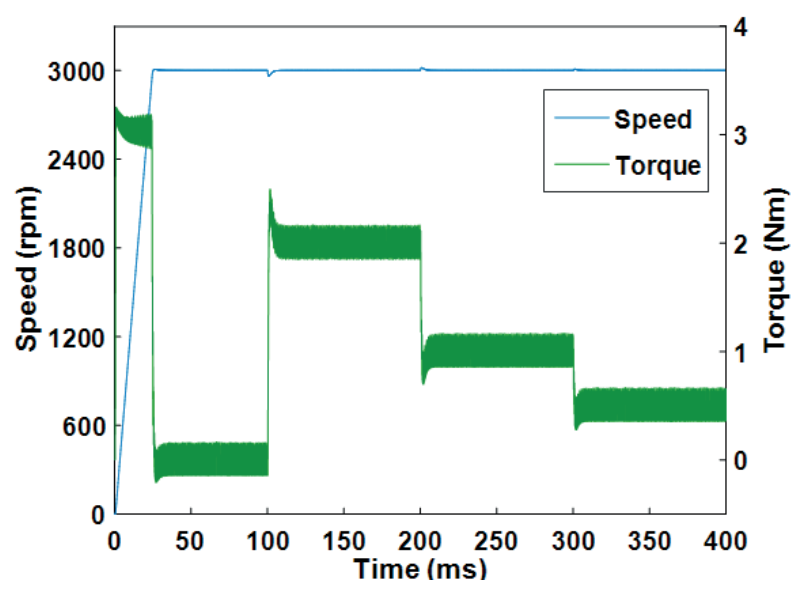

Fig. 7 The simulated process for $3000 \mathrm{rpm}$ speed-reference

Table 2 RMS torque-ripple in percentage of the mean-torque for classical DTC-SVM

\begin{tabular}{lllll}
\hline $\begin{array}{l}\text { Speed } \\
(\mathrm{rpm})\end{array}$ & & & & \\
$(\mathrm{Nm})$ & & 1000 & 2000 & 3000 \\
\hline 0.5 & 0.2429 & 0.2644 & 0.5806 & 1.1693 \\
1 & 0.0895 & 0.1393 & 0.3452 & 0.6633 \\
2 & 0.0708 & 0.08 & 0.2201 & 0.3794 \\
\hline
\end{tabular}

It will be shown that the modified DTC-SVM proposed in this article (MDTC-SVM) produces practically the same RMS torque-ripple while significantly improving the overload-capability of the drive system.

\subsection{Overload-capability problems of DTC-SVM}

Investigations carried out for classical DTC-SVM have shown that this control method is very sensitive to overload conditions. It shows poor overload-capability and instability during overload conditions. The simulated process is the following: an acceleration up to $3000 \mathrm{rpm}$ and then a load-torque step of $5 \mathrm{Nm}$ (385\% of the nominal torque) at $100 \mathrm{~ms}$ (Fig. 8). As it can be seen on Fig. 8 DTC-SVM is unable to compensate for the load-torque step.

Fig. 9 shows the torque-reference and the actual torque during this process. It can be clearly seen that DTC-SVM 
attempts to follow the torque-reference step of $7 \mathrm{Nm}$, the electromagnetic torque increases up to approximately $3.9 \mathrm{Nm}$ and then torque-control becomes unstable. Torque-reference was limited for $3 \mathrm{Nm}$ during the acceleration for $3000 \mathrm{rpm}$ in order to avoid this instability issue and make acceleration possible. $\delta$-controller was limited to $\pm \pi / 2$. Current-limit was set to $600 \%$ of the nominal current during the whole process.

Research conducted on this issue have provided sufficient evidence that the poor overload-capability and the instability is caused by the fact that in the case of classical DTC-SVM the amplitude of the stator flux vector is controlled in an open-loop fashion. Therefore, an increasing torque-error does not cause an increase in the stator flux amplitude reference signal, which leads to reduced overload-capability. Also, the instability is caused by the fact that DTC-SVM regulates torque through the load-angle only and the load-angle flows over its optimum value $\left(90^{\circ}\right)$ over time due to the fact that it is incremented by the $\delta$-controller. This can be seen on Fig. 10, which shows the load-angle in the function of time for the process illustrated by Fig. 8 and Fig. 9 .

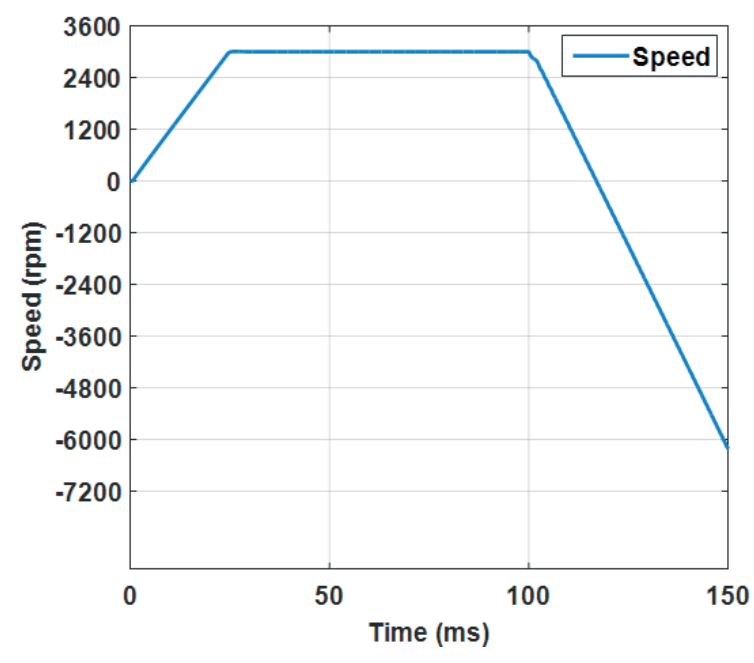

Fig. 8 The speed during overload conditions for DTC-SVM

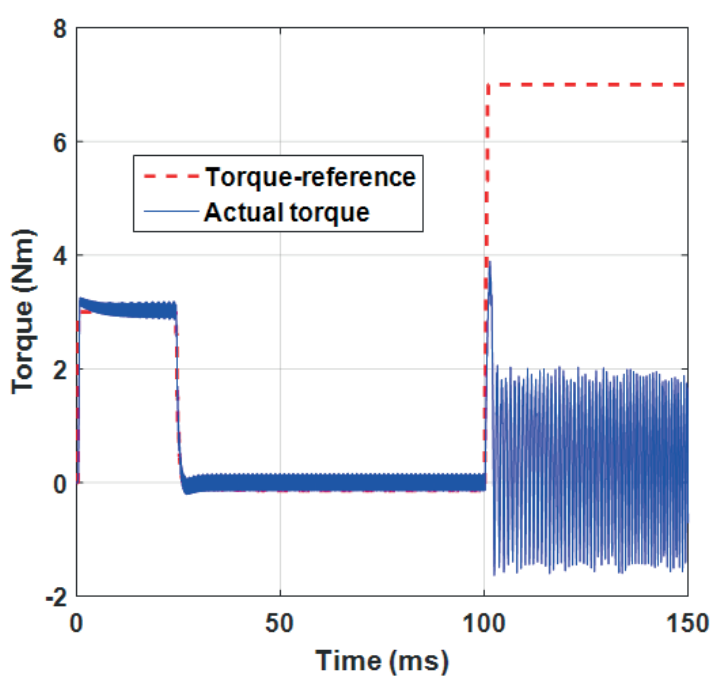

Fig. 9 The torque-reference and the actual torque during overload conditions for DTC-SVM

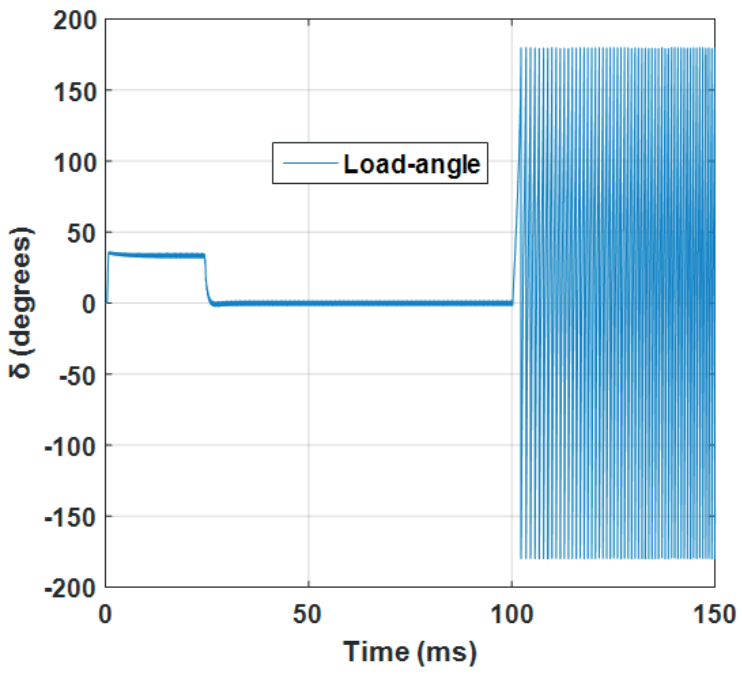

Fig. 10 The load-angle during overload conditions for DTC-SVM

Fig. 11 shows the $\delta$-increment signal, which is saturated in the most of the time because the $\delta$-controller is trying to compensate for the torque-error.

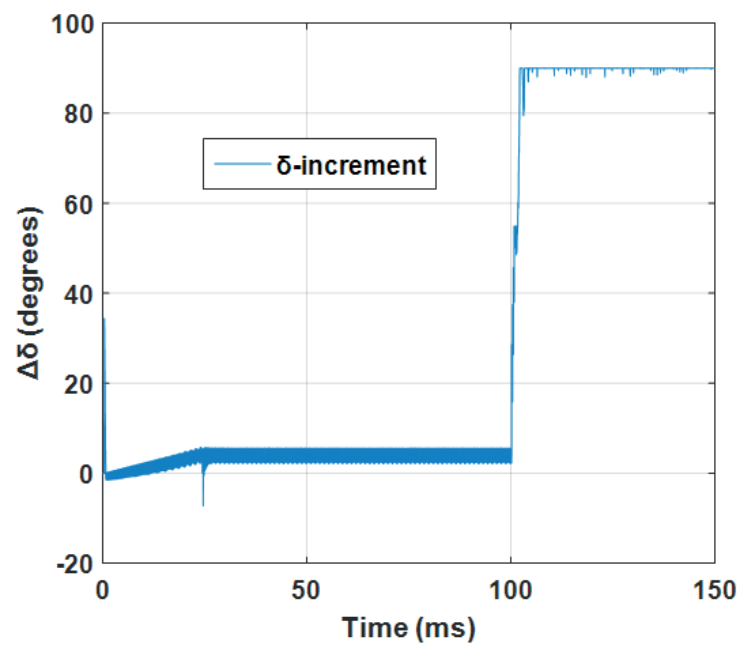

Fig. 11 The $\delta$-increment signal during overload conditions for DTC-SVM

\section{MDTC-SVM}

In order to eliminate the overload-capability problems and instability associated with classical DTC-SVM a novel DTCSVM method was invented. Fig. 12 shows the block-diagram of the MDTC-SVM. According to Fig. 12 both the predictive controller and the estimator are modified. Fig. 13 shows the block-diagram of the modified estimator (MEST).

The MEST does not calculate the electromagnetic torque. Instead, the load-angle is calculated using (33):

$$
\delta=\operatorname{atan} \frac{\psi_{q}}{\psi_{d}}
$$

The amplitude and the angle of the stator flux vector are calculated according to (27) and (28). Fig. 14 shows the block-diagram of the modified predictive controller (MPC). 


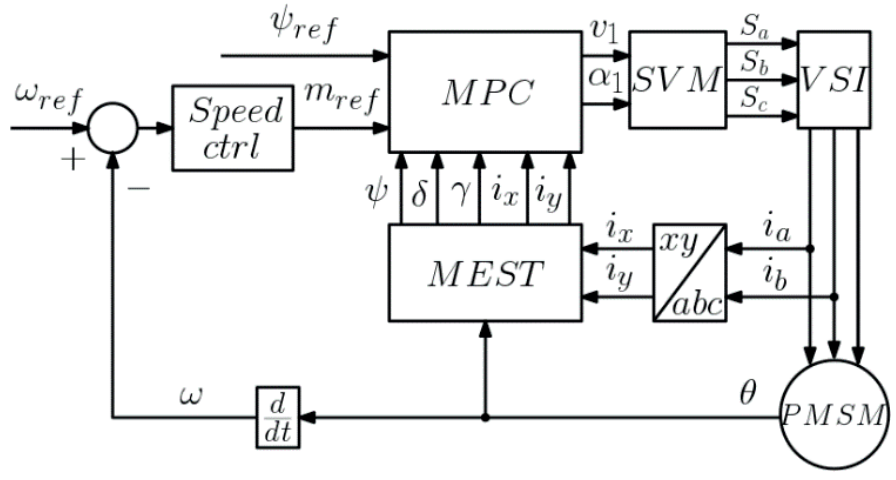

Fig. 12 MDTC-SVM

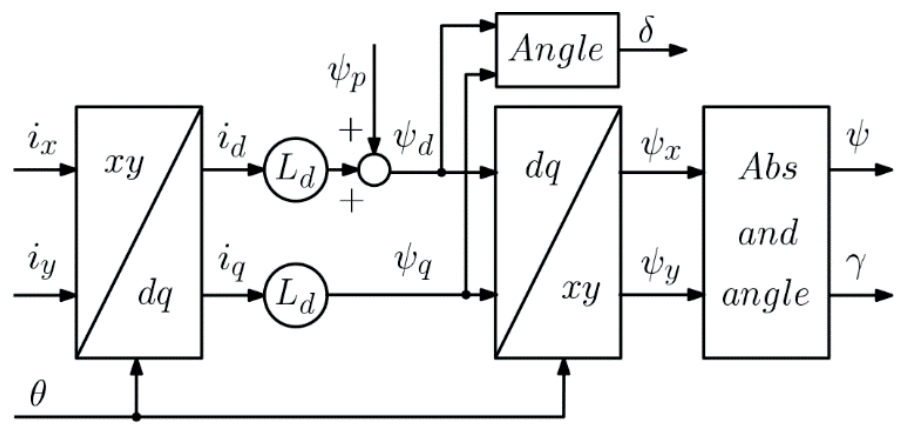

Fig. 13 MEST

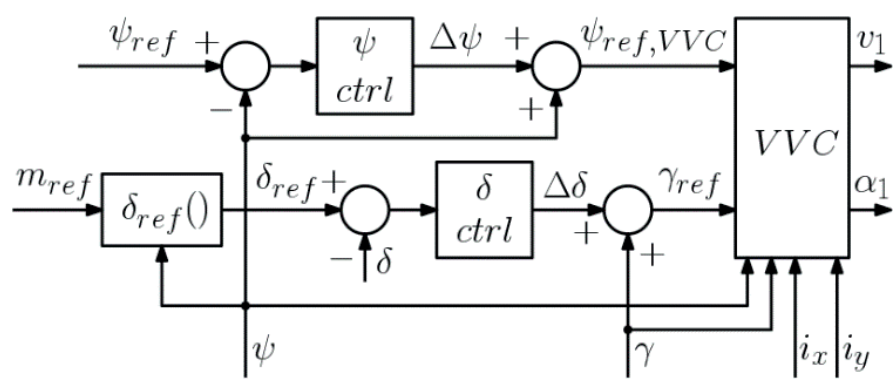

Fig. 14 MPC

The MPC regulates both the load-angle and the amplitude of the stator flux vector in a closed-loop manner. Based on the torque-reference signal the load-angle reference signal is synthesized using (34):

$$
\delta_{r e f}=\operatorname{asin}\left(\frac{2 m_{r e f} L_{d}}{3 p \psi \psi_{p}}\right)
$$

Because the load-angle regulation is based on the load-angle error signal instead of the torque-error signal (like in classical DTC-SVM on Fig. 4), the nonlinear dependency of the load-angle from the torque is excluded. This improves control performance. The $\delta$-controller $(\delta-c t r l)$ synthesizes the $\delta$-increment signal $(\Delta \delta)$ which is added to the actual angle of the stator flux vector $(\gamma)$ in order to form the stator flux angle reference signal $\left(\gamma_{\text {ref }}\right)$. Also, the $\psi$-controller $(\psi-c t r l)$ synthesizes the $\psi$-increment signal $(\Delta \psi)$ which is added to the amplitude of the stator flux vector in order to form the stator flux amplitude reference signal that is fed to the voltage vector calculator $\left(\psi_{\text {ref, } V V C},\right)$. The voltage vector calculator $(V V C)$ uses (35), (36), (25), (26) to calculate the reference voltage vector.

$$
\begin{aligned}
& v_{x, r e f}=\frac{\psi_{\text {ref }, V V C} \cos (\gamma+\Delta \delta)-\psi \cos \gamma}{T_{s}}+R i_{x} \\
& v_{y, r e f}=\frac{\psi_{r e f, V V C} \sin (\gamma+\Delta \delta)-\psi \sin \gamma}{T_{s}}+R i_{y}
\end{aligned}
$$

\subsection{Simulation results for MDTC-SVM}

Simulation was carried out for MDTC-SVM with the same parameters as for DTC-SVM in 2.4. The simulated process is the same as in 2.4. Fig. 15 shows the complete process for a 3000 rpm speed-reference. Table 3 shows the results for the RMS of the torque-ripple, which is shown in percentage of the meantorque. According to Table 2 and Table 3 there is no significant difference between classical DTC-SVM and MDTC-SVM in regard of the RMS of the torque-ripple. Also, the torque-control dynamic performance of the two methods is practically identical.

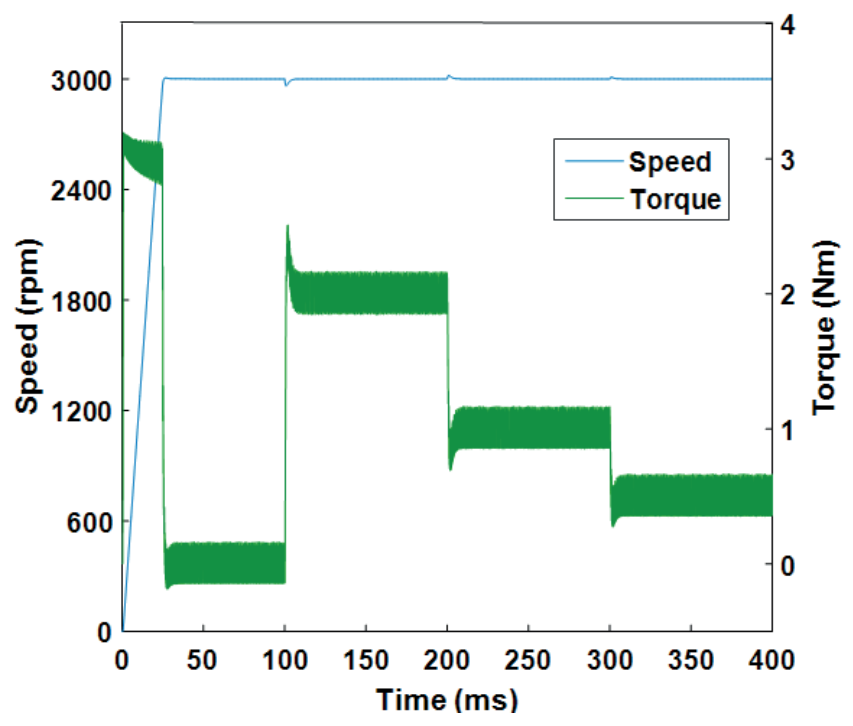

Fig. 15 The simulated process for $3000 \mathrm{rpm}$ speed-reference in the case of MDTC-SVM

Table 3 RMS torque-ripple in percentage of the mean-torque for MDTC-SVM

\begin{tabular}{lllll}
$\begin{array}{l}\text { Speed } \\
(\mathrm{rpm})\end{array}$ & & & & \\
$(\mathrm{Nm})$ & & 1000 & 2000 & 3000 \\
\hline 0.5 & 0.2404 & 0.2728 & 0.567 & 1.1685 \\
1 & 0.0812 & 0.1507 & 0.3605 & 0.6438 \\
2 & 0.0667 & 0.0861 & 0.2181 & 0.389 \\
\hline
\end{tabular}

\subsection{Overload-capability of the MDTC-SVM}

Investigations were carried out for the same process as in 2.5 with the same parameters (same current limit, etc.). Fig. 16 shows the speed in the function of time for MDTC-SVM during overload conditions, while Fig. 17 shows the torque-reference 


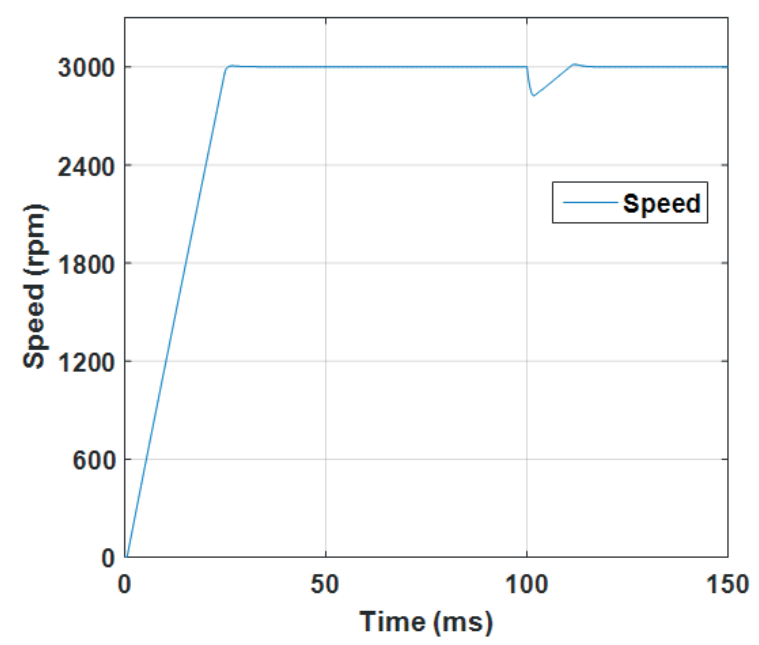

Fig. 16 The speed during overload conditions for MDTC-SVM

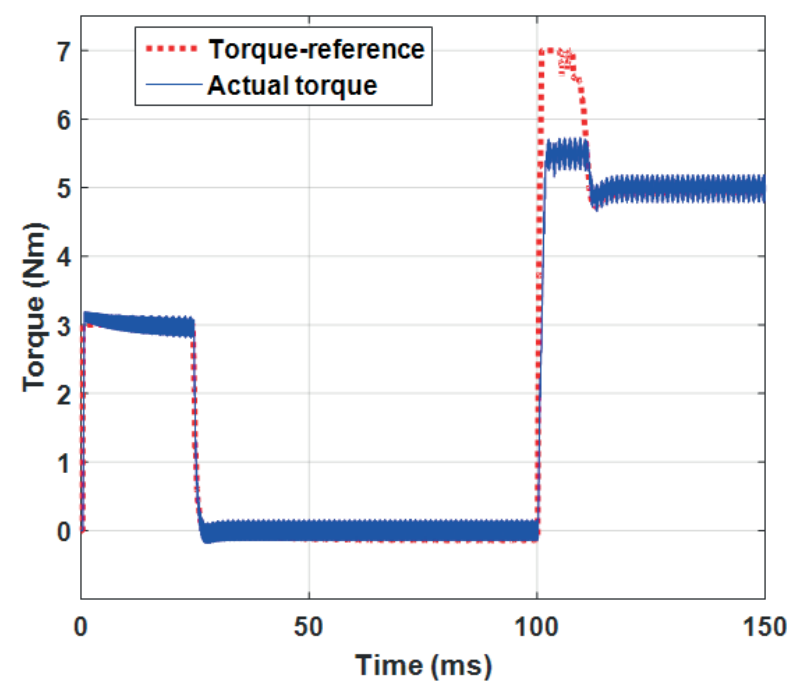

Fig. 17 The torque-reference and the actual torque during overload conditions for MDTC-SVM

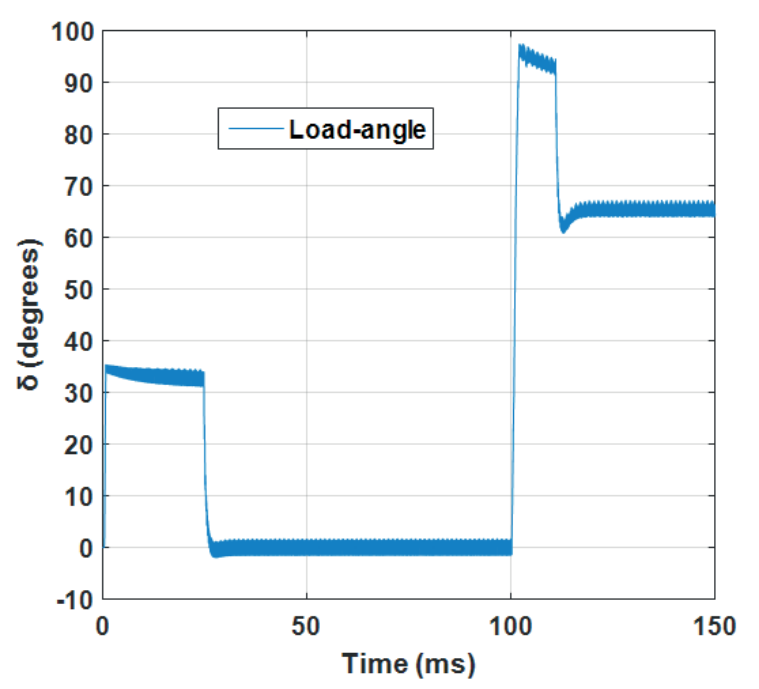

Fig. 18 The load-angle during overload conditions for MDTC-SVM

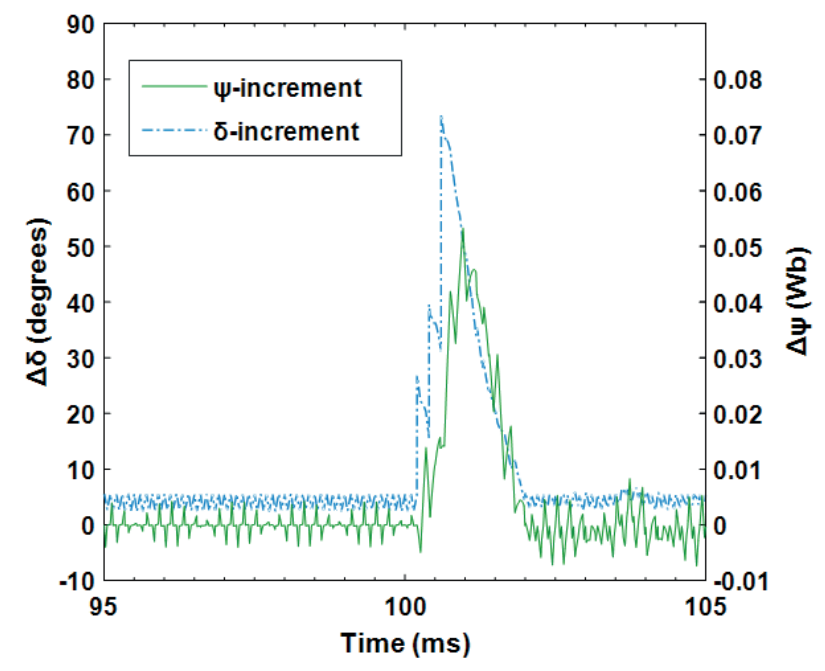

Fig. $19 \Delta \delta$ and $\Delta \psi$ during overload conditions for MDTC-SVM

indicated in Table 4 are the maximum load-torque steps that can be compensated on the specific speed with each method; these are expressed relative to the nominal torque of the motor in the brackets. However, a load-torque step greater than the one indicated in Table 4 results in that classical DTC-SVM becomes unstable, while MDTC-SVM remains stable. For example, classical DTC-SVM is capable of compensating for a load-torque step of up to $4.71 \mathrm{Nm}$ value at standstill but it is unable to compensate for a $4.72 \mathrm{Nm}$ load-torque step at standstill and becomes unstable in this case.

According to Table 4, the overload-capability of MDTCSVM is superior to that of classical DTC-SVM on every speed. In addition, the overload-capability of MDTC-SVM is practically independent of the speed, while the overload-capability of classical DTC-SVM is heavily dependent on the speed: the overload-capability decreases as the speed increases. The latter can be explained by the fact that as the speed decreases the induced voltage in the armature also decreases. Therefore, the 
voltage reserve for the $\delta$-controller (through the voltage vector calculator) is greater. This phenomenon does not have significant effect in the case of MDTC-SVM because in this case the $\psi$-controller "helps" the $\delta$-controller in generating enough voltage reserve (through the voltage vector calculator) for the compensation (see Fig. 19).

Table 4 Overload-capabilities of classical DTC-SVM and MDTC-SVM

\begin{tabular}{lll}
\hline & Classical DTC-SVM & MDTC-SVM \\
\hline $0 \mathrm{rpm}$ & $4.71 \mathrm{Nm}(362 \%)$ & $5.55 \mathrm{Nm}(427 \%)$ \\
$1000 \mathrm{rpm}$ & $4.59 \mathrm{Nm}(353 \%)$ & $5.54 \mathrm{Nm}(426 \%)$ \\
$2000 \mathrm{rpm}$ & $4.23 \mathrm{Nm}(325 \%)$ & $5.52 \mathrm{Nm}(425 \%)$ \\
$3000 \mathrm{rpm}$ & $3.78 \mathrm{Nm}(291 \%)$ & $5.5 \mathrm{Nm}(423 \%)$ \\
\hline
\end{tabular}

Lastly, Fig. 20 and Fig. 21 shows a comparison for the stability of the two methods. Fig. 20 shows the torque-reference and the actual torque for the same process as in 2.5, except that the load-torque step at $100 \mathrm{~ms}$ is of 3,79 $\mathrm{Nm}$ value. This is $0.01 \mathrm{Nm}(\approx 0.3 \%)$ greater than the value indicated in Table 4 for classical DTC-SVM on $3000 \mathrm{rpm}$ and this already causes the collapse of classical DTC-SVM.

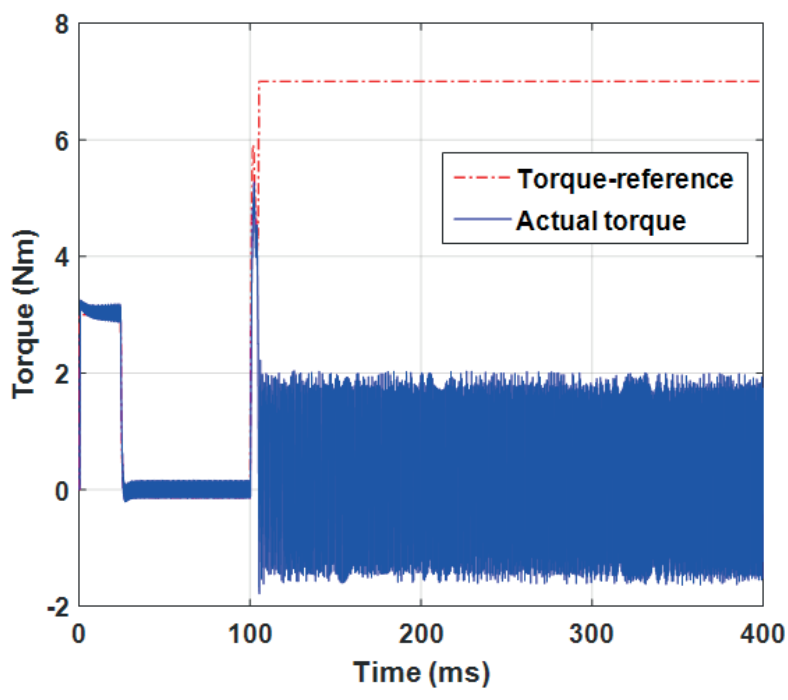

Fig. 20 Classical DTC-SVM on 3000 rpm with a load-torque step of $3.79 \mathrm{Nm}$ at $100 \mathrm{~ms}$

On the contrary, MDTC-SVM does not collapse at the beginning of the torque-transient (Fig. 21), tries to compensate for the load-torque step at $100 \mathrm{~ms}$, even though the load-torque step is of $6 \mathrm{Nm}$ value, which is $0.5 \mathrm{Nm}(\approx 9.1 \%)$ greater than the value indicated in Table 4 for MDTC-SVM on $3000 \mathrm{rpm}$.

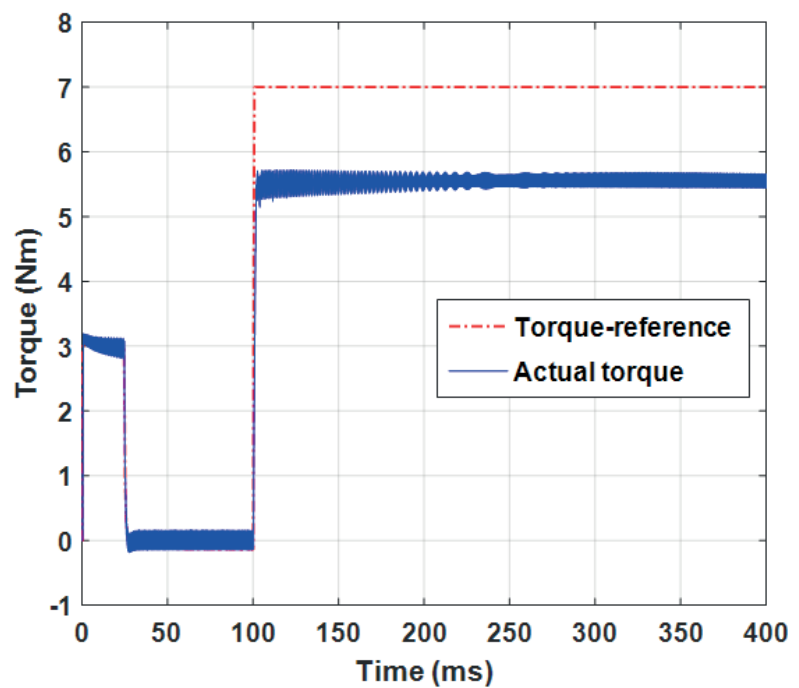

Fig. 21 MDTC-SVM on $3000 \mathrm{rpm}$ with a load-torque step of $6 \mathrm{Nm}$ at $100 \mathrm{~ms}$

\section{Conclusions}

In this article classical DTC-SVM has been analysed and it has been proven that classical DTC-SVM has severe instability-problems during overload-conditions. Therefore, a novel MDTC-SVM method was invented which is stable during overload-conditions. This MDTC-SVM method has demonstrated a far more superior (namely $45 \%$ better) overload-capability compared to classical DTC-SVM. Also, it has been concluded that the overload-capability of classical DTC-SVM is heavily dependent on the speed ( $71 \%$ difference relative to the nominal torque of the motor between standstill and $3000 \mathrm{rpm}$ ) whereas the overload-capability of MDTC-SVM is practically independent of the speed (only $4 \%$ difference relative to the nominal torque of the motor between standstill and $3000 \mathrm{rpm}$ ). These advantages of MDTC-SVM come along with the fact that there is no significant difference between classical DTC-SVM and MDTC-SVM from the point of view of the torque-ripple generated and the dynamic performance.

This MDTC-SVM method can be more effectively used for servo-systems than classical DTC-SVM because the new method has better overload-capability, its overload-capability is independent of the speed and remains stable during overload-conditions. These three advantages together can be effectively used for significantly increasing the dynamics of servo-systems.

\section{References}

[1] Świerczyński, D. "Direct Torque Control with Space Vector Modulation (DTC-SVM) of Inverter-Fed Permanent Magnet Synchronous Motor Drive, Ph.D. Thesis." Warsaw University of Technology, 2005.

[2] Świerczyński, D., Kazmierkowski, M. P. "Direct torque control of permanent magnet synchronous motor (PMSM) using space vector modulation (DTC-SVM)-simulation and experimental results." In: IEEE 2002 28th Annual Conference of the Industrial Electronics Society. IECON 02, IEEE, pp. 751-755 vol.1., 2002

https://doi.org/10.1109/IECON.2002.1187601 
[3] Świerczyński, D., Kazmierkowski, M. P., Blaabjerg, F. "DSP based direct torque control of permanent magnet synchronous motor (PMSM) using space vector modulation (DTC-SVM)." In: Proceedings of the 2002 IEEE International Symposium on Industrial Electronics, IEEE, pp. 723727, vol. 3, 2002.

https://doi.org/10.1109/ISIE.2002.1025821

[4] Schmidt, I., Veszprémi, K. "Drive Control." Budapest, 2012.

[5] Schmidt, I., Vincze, G., Veszprémi, K. "Villamos szervo-és robothajtások." (Electric servo- and robot drives.), Múegyetemi Kiadó, Budapest, 2000. (in Hungarian)

[6] Veszprémi, K. "Váltakozóáramú villamos hajtások hálózatcsatlakozási tulajdonságainak optimalizálása." (The optimization of network-connections of AC electric drives.), Hungarian Academy of Sciences (MTA), Budapest, 2009. (in Hungarian)

[7] Vas, P. "Sensorless Vector and Direct Torque Control." Oxford University Press, Oxford, 1998.

[8] Juhász, G., Halász, S., Veszprémi, K. "New aspects of a direct torque controlled induction motor drive." In: Proceedings of IEEE International Conference on Industrial Technology 2000, 2000, pp. 43-48 vol.1. https://doi.org/10.1109/ICIT.2000.854094

[9] Juhász, G., Halász, S., Veszprémi, K. "Simulation and Measurement of Direct Torque Controlled IM Drive." In: Conference on Power Electronics and Motion Control: EPE'PEMC'2000, 2000.09.05-2000.09.07, pp. 124-129., Košice, Slovakia.

[10] Niu, F., Wang, B., Babel, A. S., Li, K., Strangas, E. G. "Comparative Evaluation of Direct Torque Control Strategies for Permanent Magnet Synchronous Machines." IEEE Transactions on Power Electronics. 31(2), pp. 1408-1424. 2016. https://doi.org/10.1109/TPEL.2015.2421321

[11] Veszprémi, K. "Optimizing the Dynamic Behavior of Direct Controls of Voltage-source Converters." Electric Power Components and Systems. 37(9), pp. 1014-1035. 2009. https://doi.org/10.1080/15325000902918883

[12] Veszprémi, K., Wallner, M., Patonay, G. "Frekvenciaváltók közvetlen szabályozása." (Direct control of frequency converters.) Elektrotechnika. 108(3), pp. 5-8. 2015. (in Hungarian)

[13] Vajsz, T., Számel, L. "Állandómágneses forgórészü szinkron motorok közvetlen nyomatékszabályozása." (Direct torque control of permanent magnet synchronous motors.) In: V. Mechwart András Ifjúsági Találkozó, Magyar Elektrotechnikai Egyesület (MEE), Budapest, 2015. (in Hungarian)

[14] Yang, Y., Hunag, R., Yu, Y.-P., Wang, S. "Direct torque control of permanent magnet synchronous motor based on space vector modulation control." In: 8th International Power Electronics and Motion Control Conference (IPEMC-ECCE Asia), IEEE, pp. 1818-1821, Hefei, 2016, https://doi.org/10.1109/IPEMC.2016.7512570

[15] Xie, W., Wang, X., Dajaku, G., Gerling, D., Kennel, R. "Improvement and comparison of efficiency and low cost drive system based on DTC and DTC-SVM." In: 2013 International Electric Machines \& Drives Conference, IEEE, pp. 1261-1266, Chicago, 2013. https://doi.org/10.1109/IEMDC.2013.6556296

[16] Abassi, M., Khlaief, A., Saadaoui, O., Chaari, A., Boussak, M. "Performance analysis of FOC and DTC for PMSM drives using SVPWM technique." In: 16th International Conference on Sciences and Techniques of Automatic Control and Computer Engineering (STA), IEEE, pp. 228233, Monastir, 2015. https://doi.org/10.1109/STA.2015.7505167

[17] Basar, M. S., Bech, M. M., Andersen, T. O., Scavenius, P., ThomasBasar, T. "Comparison of sensorless FOC and SVM-DTFC of PMSM for low-speed applications." In: 4th International Conference on Power Engineering, Energy and Electrical Drives, IEEE, pp. 864-869, Istanbul, 2013. https://doi.org/10.1109/PowerEng.2013.6635723
[18] Teng-fei, C., Chong-wei, H., Yi-na, X., Yu-he, Z. "Research on SVMBased Direct Torque Control for PMSM of Artillery Speed." In: 2013 25 th Chinese Control and Decision Conference (CCDC), IEEE, pp. 37273730, Guiyang, 2013, https://doi.org/10.1109/CCDC.2013.6561596

[19] Weijie, L., Jinsong, R., Dongliang, L., Qiuxuan, W. "Evaluation on Direct Torque and Flux Control of IPMSM for Electric Vehicle." In: 34th Chinese Control Conference (CCC), IEEE, pp. 4355-4360, Hangzhou, 2015. https://doi.org/10.1109/ChiCC.2015.7260314

[20] Bin, Q., Xuexiang, J., Xin, W., Ceng, S. "Electric pitch PMSM servo system based on direct torque control." In: 2013 Chinese Automation Congress, IEEE, pp. 442-447, Changsha, 2013. https://doi.org/10.1109/CAC.2013.6775775.

[21] Abosh, A. H., Zhu, Z., Ren, Y. "Reduction of Torque and Flux Ripples in Space-vector Modulation based Direct Torque Control of Asymmetric Permanent Magnet Synchronous Machine." IEEE Transactions on Power Electronics. 32(4), pp. 2976-2986. 2016. https://doi.org/10.1109/TPEL.2016.2581026

[22] Zhao, K.-Q., Qi, Z.-Y., Zhong, X. "A new direct torque controller to reduce torque ripple for permanent magnet synchronous motor drives." In: IECON 2013 - 39th Annual Conference of the IEEE Industrial Electronics Society, IEEE, pp. 2348-2353, Vienna, 2013. https://doi.org/10.1109/IECON.2013.6699498

[23] Ya, G., Yi, G. "Research of PMSM fuzzy direct torque controller based on sliding mode observer." In: IEEE International Conference on Mechatronics and Automation, IEEE, pp. 17-21, Harbin, 2016. https://doi.org/10.1109/ICMA.2016.7558527

[24] Huang, J., Xu, Q., Shi, X., Cui, L., Xiang, Z. "Direct torque control of PMSM based on fractional order sliding mode variable structure and space vector pulse width modulation." In: Proceedings of the 33rd Chinese Control Conference, pp. 8097-8101, Nanjing, 2014.

https://doi.org/10.1109/ChiCC.2014.6896355

[25] Mostafavi, H., Sadeghi, M., Panah, P. G., Azizkhani, S. "Fuzzy direct torque control of IPMSM to improve both efficiency and speed response," in IEEE International Conference on Information and Automation, IEEE, pp. 512-517, Shenyang, 2012. https://doi.org/10.1109/ICInfA.2012.6246860.

[26] Vafaie, M. H., Dehkordi, B. M., Moallem, P., Kiyoumarsi, A. "A New Predictive Direct Torque Control Method for Improving Both SteadyState and Transient-State Operations of the PMSM." IEEE Transactions on Power Electronics. 31(5), pp. 3738-3753. 2016. https://doi.org/10.1109/TPEL.2015.2462116

[27] Vafaie, M. H., Dehkordi, B. M., Moallem, P., Kiyoumarsi, A. "Improving the Steady-State and Transient-State Performances of PMSM through an Advanced Deadbeat Direct Torque and Flux Control System." IEEE Transactions on Power Electronics. 32(4), pp. 2964-2975. 2016. https://doi.org/10.1109/TPEL.2016.2577591

[28] Vafaie, M. H., Dehkordi, B. M., Moallem, P., Kiyoumarsi, A. "Minimizing Torque and Flux Ripples and Improving Dynamic Response of PMSM Using a Voltage Vector With Optimal Parameters." IEEE Transactions on Industrial Electronics. 63(6), pp. 3876-3888. 2016. https://doi.org/10.1109/TIE.2015.2497251

[29] Kendouci, K., Mazari, B., Benhadria, M. R., Dadi, R. "Speed-sensorless direct torque and flux control of PMSM based on extended Kalman filter using space vector modulation." In: 3rd International Conference on Control, Engineering \& Information Technology (CEIT), IEEE, pp. 1-5, Tlemcen, 2015. https://doi.org/10.1109/CEIT.2015.7233045

[30] Vajsz, T., Számel, L. "Robust speed-control for permanent magnet synchronous motor servo drives." In: Proceedings of the Workshop on the Advances of Information Technology: WAIT 2015, pp. 78-82, Budapest University of Technology and Economics Department of Control Engineering and Information Technology, Budapest, 2015. 
[31] Vajsz, T., Számel, L. "An investigation of robust speed-controllers for permanent magnet synchronous motor servo drives." in Proceedings of the Automation and Applied Computer Science Workshop 2015: AACS'15, pp. 117-128, Budapest University of Technology and Economics Department of Automation and Applied Informatics, Budapest, 2015.

[32] Vittek, J., Vavrus, V., Malek, M., Buchner, P., Michalik, W. "Prescribed closed-loop speed dynamics control of the actuator employing linear permanent magnet synchronous motor." In: 2005 IEEE International Conference on Industrial Technology, IEEE, pp. 604-609, 2005. https://doi.org/10.1109/ICIT.2005.1600709

[33] Schmidt, I., Vincze, K., Veszprémi, K. "Vector Sliding Mode Control of Sinusoidal-Field Synchronous Servo Drive." Periodica Polytechnica Electrical Engineering. 45(1), pp. 65-77. 2001.

[34] Schmidt, I., Vincze, K., Veszprémi, K., Seller, B. "Adaptive hysteresis current vector control of synchronous servo drives with different tolerance areas." Periodica Polytechnica Electrical Engineering. 45(3-4), pp. 211-222. 2001.
[35] Veszprémi, K., Schmidt, I. "Direct controls in voltage-source converters - generalizations and deep study." In: 2008 13th International Power Electronics and Motion Control Conference, IEEE, pp. 1803-1810, Poznan, 2008. https://doi.org/10.1109/EPEPEMC.2008.4635527

[36] Schmidt, I., Veszprémi, K. "Application of direct controls to variablespeed wind generators." In: 2005 International Conference on Industrial Electronics and Control Applications, IEEE, pp. 1-6, Quito, 2005. https://doi.org/10.1109/ICIECA.2005.1644340

[37] Chikha, S., Barra, K. "Predictive Control of Variable Speed Wind Energy Conversion System with Multi Objective Criterions." Periodica Polytechnica Electrical Engineering and Computer Science. 60(2), pp. 96106, 2016. https://doi.org/10.3311/PPee.8873

[38] Mahlfeld, H., Schuhmann, T., Döbler, R., Cebulski, B. "Impact of overmodulation methods on inverter and machine losses in voltage-fed induction motor drives." In: XXII International Conference on Electrical Machines (ICEM), IEEE, pp. 1064-1070, Lausanne, 2016. https://doi.org/10.1109/ICELMACH.2016.7732657 